\title{
Cyber Security, Forensics and Its Impact on Future Challenges in Saudi Arabia Smart Cities Case Study on the Modern, Urban Planning and Design
}

\author{
Mahmood Abdulghani Alharbe ${ }^{1}$ \\ ${ }^{1}$ Department of Computer Information Systems, Taibah University, Almadinah Saudi Arabia \\ mharbie@taibahu.edu.sa
}

\begin{abstract}
This study discloses major challenges of maintaining smart cities in Saudi Arabia. The smart city provides several amazing facilities for the population of the city that ensures the effective e-governance system with data-driven decision-making. The major challenges of smart cities include maintenance of modern technology and infrastructure, public awareness regarding usage of digital equity, cyber security, forensics etc. The research initiatives reveal the impacts of cyber security and forensics on modern and urban planning \& design in Saudi Arabia that ensure the protection from unethical practices like cybercrime by using holistic and comprehensive strategy. Based on the review of significant literatures and analysis of the selected articles, the findings provide the gap between challenges for smart cities in Saudi Arabia and actual initiatives to protect through cyber security and forensics. The results of the present study describe the implementation of cyber security and forensics to protect from illegal access of valuable information and occurrences happening physical disruptions in public services for smart cities in Saudi Arabia. The outcomes of the research work revealed the positive impacts and prospects of revolutionary changes of developing and maintaining smart cities by implementing modern and urban strategic planning and design.
\end{abstract}

Key words : Smart City, Cyber security, Forensics, Cybercrime Holistic, Comprehensive Strategy

\section{INTRODUCTION}

Highlight a section that you want to designate with a certain style, then select the appropriate name on the style menu.

The smart city concept developed in the area of technology, infrastructure, smart human resources, research and development, good value of education, energy efficiency, data management and intelligent security system for the general public. However over the world there are many cities marked as smart and intelligent such as Washington, London, New York from the side of western countries or Tokyo, Dubai, Singapore, Melbourne, Hong Kong from other side of world as well as Seoul, Ahmedabad, Shanghai, Beijing, Sydney etc. [6]. These smart cities developed their structure by ensuring and guaranteeing some of smart workforce, digital inclusion, innovation, sharing knowledge across, open data system, smart leadership models that provides the greatest and ultimate security with diverse areas of prospects for the population [1] [14]. All the extra-ordinary facilities and better securities attract the diverse professionals to migrate from various corners of the world [5] [33]. Because of geographical location and contrasting climate, the most of the cities in Saudi Arabia could not take part of the main stream of becoming smart city [28]. With the great difficulties, the desert cities namely Riyadh, Jeddah, Al Madinah, Ad-Dammam, Mecca etc. projected the city of opportunity, security towards the quality of life and attracts the world population by implementing Innovative construction, Artificial intelligence, Autonomous vehicles, Digitization and Sustainability [2]. The frequent and unbalanced growth of world population is the major challenge especially for smart cities. Similarly, the smart cities in Saudi Arabia also faced the same problems and reflect the statistics of $689 \%$ increase of residents against of $146 \%$ of world population in the duration of last 56 years [27]. The increased population in Saudi Arabia demands the smart transportation facilities, adequate power plants, proper water supply networks, smart waste management system, detection of criminal activities, information and communication technology, quality education system, modern hospitals and other community services [15]. The modern technology, Internet of Things (IoT), e-governance system support to collect real time data, identifies and analyzes the potential challenges to accomplish assets and resources efficiently [13]. The background and previous studies that has been written by this chapter "Introduction" to describe the variation and modification of 
the manuscript with other researches and studies, that it is innovative, it are used in the chapter " Objectives With Hypothesis Testing "to explain the aims and way to study. Then "Research Method" comes to refer to the process of investigation as well as added to explain briefly the theory and/or the proposed method/algorithm. After that its employed in the next section "Results and Discussion" to provide for the analysis of the conclusions [4].

\section{TESTING LITERATURE REVIEW}

The digital society revealed all the information through digital media and accessible by the common people which are dangerous for protecting and ensure the safety, security and privacy. The authors examined the major problems and challenges for ensuring security and privacy in smart cities. The findings of the study revealed the importance of awareness programs among the general public and protect themselves from any probable threats [7]. The smart cities should ensure the better infrastructure, major utility facilities, privacy and security of assets and other materials. Using latest technology and Internet of Things (IoT), smart banking operations, secured password for access of data can protect the entire operations in smart cities [8] [17]. The increased migration in Saudi Arabia became the major threats for the smarts cities in the Kingdom. Because of construction, the workers are migrating to the smart cities, the diverse professionals are migrating for providing world class services, and younger generations are attracted by the potential job opportunities [12]. The expansion of smart city limits time to time for urbanization and migration in Saudi Arabia faces the threats of sustainable society [31] [32]. The big data analysis and proper implementation of Internet of Things (IoT) can control and protect the smart cities from several threats. The digital society revealed all the information through digital media and accessible by the common people which are dangerous for protecting and ensure the safety, security and privacy [16]. The digital life expects adequate sources of open access data for fulfilling the day to day persistence and operations. Because of illegal access and implementation of data sources for unethical practices disrupt the sharing process of valuable data and expert opinion [25]. Based on the present research study, the curiosity of the research reflects in identifying the future challenges for Smart Cities in Saudi Arabia especially in cyber security and forensics and its impact on modern and urban planning and design [3]. The challenges of sustainable development are identified for frequent urbanization in Saudi Arabia and difficulties to control the unauthirsed infrastructure in all the big cities. Because of future opportunities, a large portion of population migrating from several areas of Saudi Arabia and rest of the world that revealed the major security issues and increases the unorganized sectors [1] [26]. This was found that the imbalanced level of population in big cities of Saudi Arabia demand the adequate level of electricity supply, water supply, construction of building and other facilities [4] [9]. Furthermore, each processes and services in that case are operated by a majority part of outsiders which threats by concerning of privacy in the intelligent and IT cities [34]. The local government initiates the security and privacy concerns through the big data analysis and Internet of Things (IoT) that can control and protect the smart cities from several threats [2].

\section{OBJECTIVES WITH HYPOTHESIS TESTING}

The important objectives have been identified when the researchers were keeping in mind the few related research questions. The first question was "Whether the trends of population growth influence the smart city concept in Saudi Arabia? The objective was to find out the trends of population growth and its impact on Smart Cities in Saudi Arabia. The second question was "What are the future challenges for Smart Cities in Saudi Arabia? The objective was to identify the future challenges for Smart Cities in Saudi Arabia. The question was "What are the probable impacts of Cyber security and forensics on modern and urban planning and design?" The objective was to find out the impacts of Cyber security and forensics on modern and urban planning and design. The last question was "Whether the strategies can to protect the smart cities from future challenges? The last objective was to identify the strategies to protect the smart cities from future challenges. The purposeful research methodology considered the hypothesis H01: All the six strategies together do not have impact on future challenges of smart cities for the modern and urban planning and design Or, Mathematically, H01: [The impact of six strategies together on future challenges of smart cities for the modern and urban planning and design $]=0$.

\section{RESULTS AND DISCUSSION}

The required data were collected and arranged systematically. The systematic arranged data were coded for easily identification and separation. The data were analyzed by employing the statistical techniques of Normality Test, Mean, Standard Deviation, and Coefficient of Variation to obtain the hidden patterns with respect to Online Security Challenges in Saudi Smart Future Cities with the consideration of Safety, Security and Privacy. The research work intends to accomplish the objectives of the study by holistically investigating various strategies to solve problems of Online Security Challenges in Saudi Smart Future Cities.

\section{RESEARCH METHOD}

The present study makes an attempt to identify the future challenges for smart cities in Saudi Arabia and in implementing the strategies for overcoming those challenges that influence the Modern and Urban Planning and Design. The requisite data were collected from secondary as well as primary sources and clarified with existing sources. The primary data were collected from the target audience like experts, economists, engineers, management consultant, private and government employees from Riyadh, Jeddah, Al Madinah, Ad-Dammam, and Mecca. The several and related 
responses were collected, filtered and evaluated to prepare research report. Research methodology is the combination of methods of data collection and methods of data analysis after research design.

\subsection{Influence of Population Smart Cities In SA}

The smart cities in Saudi Arabia attract the population from different corner of the world. The statistics in the Table-1 shows the population growth of smart cities in Saudi Arabia since 1980. The population growth of Riyadh expecting since 1980 to 2030 is 710 percentages which is the major challenge to implement technology and provide all smart facilities for the city population. Similarly, the population of Jeddah is expecting from 1980 to 2030 is around 533 percentage of growth. The population of $\mathrm{Al}$ Madinah is expecting from 1980 to 2030 is around 514 percentage of growth. The population of Ad-Dammam is expecting from 1980 to 2030 is around 654 percentage of growth. The population of Macca is expecting from 1980 to 2030 is around 374 percentage of growth.

Table 1: Graphical representation Changes and expected of population between years 1980 and 2030 of 5 smart cities in Saudi Arabia

* Expected Population in the year 2020, ** Expected Population in the year 2030

Source: Compiled by the Writers

\begin{tabular}{|c|c|c|c|c|c|c|c|}
\hline Smart Cities in Saudi Arabia & 1980 & 1990 & 2000 & 2010 & $2020\left(^{*}\right)$ & $2030(* *)$ & Changes of Population $(\%)$ \\
\hline Riyadh & $1,055,000$ & $2,325,000$ & $3,567,000$ & $5,220,000$ & $7,231,000$ & $8,547,000$ & \\
\hline Jeddah & 851,000 & $1,742,000$ & $2,509,000$ & $3,450,000$ & $4,610,000$ & $5,388,000$ & 710 \\
\hline Al Madinah & 284,000 & 529,000 & 795,000 & $1,106,000$ & $1,489,000$ & $1,744,000$ & 533 \\
\hline Ad-Dammam & 196,000 & 409,000 & 639,000 & 909,000 & $1,253,000$ & $1,478,000$ & 514 \\
\hline Mecca & 501,000 & 856,000 & $1,168,000$ & $1,543,000$ & $2,042,000$ & $2,379,000$ & 654 \\
\hline
\end{tabular}

survival of normal life with open access data resources, which is one of the major challenges of smart cities especially in

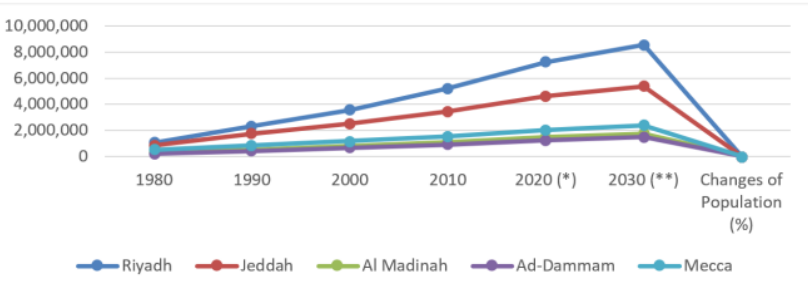

Figure 1 Graphical representation Changes and expected of population between years 1980 and 2030 of 5 smart cities in Saudi Arabia .

*Expected Population in the year 2020,

** Expected Population in the year 2030

Source: Compiled by the Writers

\subsection{Challenges for Smart Cities SA}

The development of smart and intelligent city is the revolutionary initiative that provides all round modern facilities for the citizens [10]. Latest technology and management approaches in smart cities ensure the best quality of balancing life with ease of doing business, quality and good value of education, research and development, adequate electricity supply, water supply, transparency of information sharing process, security of assets and properties [11] [31]. But, the governors of smart cities are facing several challenges which make sometime bad or good effects on the side of life such as Lack of IT Infrastructure, Artificial Intelligence, Cybercrime, Fund Generation, Lack of Strategic Plan and Limited of Energy Resources [18]. The research articles and expert opinion indicates the probable threats of smart cities in Saudi Arabia and most frequency of occurrence in percentage are recorded in the table no. 2 .

Table 2 Compare The Better Alternative Between Artificial Intelligence And Smart Operations For The Future Challenges For Smart Cities In Saudi Arabia

Source: Compiled by the Writers

\begin{tabular}{|l|c|}
\hline Challenges for Smart Cities & Frequency of Occurrence \% \\
\hline Cybercrime & 28 \\
\hline Limited of Energy Resources & 12 \\
\hline Lack of IT Infrastructure & 18 \\
\hline Fund Generation & 10 \\
\hline Artificial Intelligence & 20 \\
\hline Lack of Strategic Plan & 12 \\
\hline
\end{tabular}

Intelligence, Cybercrime, Fund Generation, Lack of Strategic Plan and Limited of Energy Resources [18]. The research articles and expert opinion indicates the probable threats of smart cities in Saudi Arabia and most frequency of occurrence in percentage are recorded in the table no. 2. The smart cities are the witness of cybercrime that has negative impacts on Saudi Arabia [23]. The migration of population from different corner of the world becomes the extra burden for the administrators of few smart cities in Saudi Arabia that demands the large quantity of energy resources. Lack of IT infrastructure is another challenge for smart cities to protect from corruption, fraud and crimes [22]. The fund generation is the important step for modern infrastructure [29]. The administrators approach World Banks, IMF, and the National and International organizations for investment and promise to refund the money which is another challenge [24].

Artificial intelligence is the better alternative for the smart operations by machines like computer systems. Nevertheless the mechanized and automated system that changes the human efforts and engagements is artificial intelligence. Lack of strategic plan in smart cities is the challenge of attracting the skilled and professionals form various countries.

\subsection{Strategies For Challenges Of Smart Cities}

Smart city concept not only brings the opportunities for the citizen, also includes several challenges. However, we can reduce those challenges by making realistic action plan as well as to do the systematic observation. 


\subsubsection{Cyber Security and Forensic Investigation}

Cyber security and Forensic Investigation process are the smart initiatives that can control the cybercrime and hacking activities. The administration of smart city takes initiatives for preventing institutional crime, social crime and cybercrime by continuous monitoring of several regular operations in all the areas.

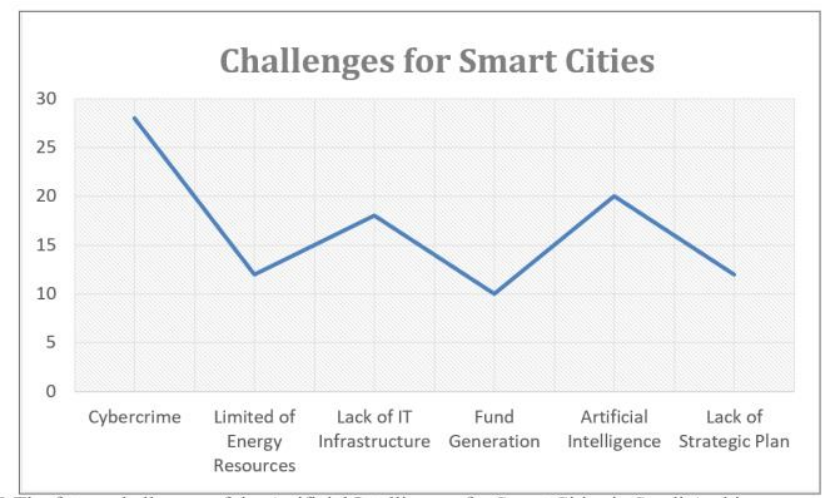

Figure 2 The future challenges of the Artificial Intelligence for Smart Cities in Saudi Arabia.

Source: Compiled by the Writers

\subsubsection{Production of Renewable Energy}

Because of repeated usage of non-renewable resources by large population, there will be a limited period of time to survive with those resources. The production of renewable resources is the revolutionary initiatives to overcome future challenges.

Table 3 Details about the strategies for overcoming the challenges of smart cities in Saudi Arabia. Source: Compiled by the Writers

\begin{tabular}{|l|c|}
\hline $\begin{array}{l}\text { Strategies For Overcoming } \\
\text { The Challenges }\end{array}$ & $\begin{array}{l}\text { Frequency of Occurrence } \\
\text { in Percentage }\end{array}$ \\
\hline $\begin{array}{l}\text { Cyber security and Forensic } \\
\text { Investigation }\end{array}$ & 29 \\
\hline $\begin{array}{l}\text { Production of Renewable } \\
\text { Energy }\end{array}$ & 12 \\
\hline Smart IT Infrastructure & 22 \\
\hline $\begin{array}{l}\text { Public-private funding } \\
\text { mechanism }\end{array}$ & 11 \\
\hline $\begin{array}{l}\text { Implementation of Artificial } \\
\text { Intelligence }\end{array}$ & 9 \\
\hline Strategic road mapping & 17 \\
\hline
\end{tabular}

\subsubsection{Smart IT Infrastructure}

Smart IT infrastructure is the most required step to safeguard the open access data, assets and property of general public with real time monitoring system. More Often Than Not, it can a complete and multi-lingual ICT resolution and technology, particularly created for stakeholders in supplying of IT-based software services with smart devices for IT Infrastructure management.

\subsubsection{Public-Private Funding Mechanism}

Similarly the public-private funding mechanism fulfills the requirements of huge fund generation for modern infrastructure. Typically, funding mechanisms cover the margin of funds which offer international funding organizations (IFOs) who can support smart cities wherever.

\subsubsection{Implementation of Artificial Intelligence}

The implementation of artificial intelligence reduces the error of operation and maintenance that will give the better solutions for smart city operations. Some research mentioned into the development of AI by key applied issues into existing workflows, including data standardization, and interoperability across several web pages [19] [30]. Also, it added some issues such as transparency of algorithms, data sharing and privacy.

\subsubsection{Strategic Road Mapping}

Finally, the strategic road mapping facilitates fulfillments of vision and mission of the smart city administrators and their smooth operations towards sustainable development. Also, it used as approach for advocating modernization and strategy, at both societies and cities levels. A key advantage is the communication related with the enhancement and dissemination of roadmaps, especially for aligning technology and profitable perspectives.

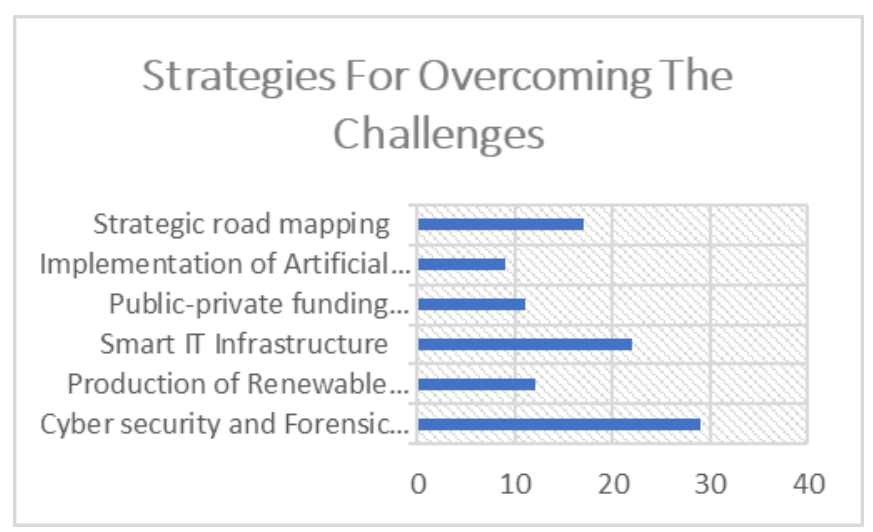

Figure 3 Graphical Representations Of The Strategies For Overcoming The Challenges For Smart Cities In Saudi Arabia

\section{RESULTS AND ANALYSIS}

Multiple Regression Analysis was employed and the summary of the results is shown in the Table 4. Various experts, economists, business practitioners were the respondents who have given the valuable impressions regarding the future challenges of Smart Cities in Saudi Arabia. The results and discussion also revealed the strategies for overcoming those challenges of smart cities. H01: All the 
six strategies together do not have impact on future challenges of smart cities for the modern and urban planning and design. Or, Scientifically, if we focus on the main Hypothesis Testing H01: [The impact of six strategies together on future challenges of smart cities for the modern and urban planning and design $]=0$. The null hypothesis $(\mathrm{H} 01)$ was tested under two categories namely ANOVA Test (Regression Analysis) and t-test. ANOVA Test (Regression Analysis) was employed to confirm about the impact of six strategies together on future

Table 4 The Influence of Six Strategies For Cyber Security, Forensics In Saudi Arabia Smart Cities.

Source: Compiled by the Writers adequate electricity supply, water supply, transparency of information sharing process, security of assets and properties [20]. The present research study was concentrated on identifying the effective strategies for overcoming those future challenges. Various strategies for overcoming the challenges were identifying cyber security and forensic investigation, production of renewable energy, smart IT infrastructure, public-private funding mechanism, implementation of artificial intelligence and strategic road mapping. Cyber security and Forensic Investigation process are the smart initiatives can control the cybercrime and hacking activities. Because of repeated usage of non-renewable resources by large population,

\begin{tabular}{|c|c|c|c|c|c|}
\hline \multicolumn{6}{|c|}{ Highlights of Multiple Regression Analysis } \\
\hline \multicolumn{6}{|c|}{$\begin{array}{c}\text { Dep Var: Strategies, N: 400, Multiple R: } 0.677, \text { Squared multiple R: } 0.479 \text {, } \\
\text { Adjusted Squared Multiple R: 0.514, Standard error of estimate: } 0.89\end{array}$} \\
\hline \multicolumn{6}{|c|}{ Summary of Multiple Regression Analysis } \\
\hline Effect & Coeff & Std Error & Std Coeff & Tolerance & $\mathbf{t}$ \\
\hline Constant & -4.302 & 0.609 & 0.000 & - & -7.064 \\
\hline Cybercrime & -0.054 & 0.029 & -0.116 & 0.256 & -2.729 \\
\hline $\begin{array}{l}\text { Limited of Energy } \\
\text { Resources }\end{array}$ & 0.327 & 0.066 & 0.307 & 0.271 & $3.882 * *$ \\
\hline Lack of IT Infrastructure & 0.766 & 0.074 & 0.739 & 0.201 & $9.832 * *$ \\
\hline Fund Generation & 0.314 & 0.060 & 0.304 & 0.304 & $6.225 * *$ \\
\hline Artificial Intelligence & 0.342 & 0.054 & 0.386 & 0.275 & $6.814 * *$ \\
\hline Lack of Strategic Plan & -0.515 & 0.049 & -0.599 & 0.314 & $-8.968 * *$ \\
\hline \multicolumn{6}{|l|}{$* *$ Significant at 0.01 level } \\
\hline \multicolumn{6}{|c|}{ Analysis of Variance (ANOVA) } \\
\hline Source & Sum-of-Squares & df & Mean-Square & \multicolumn{2}{|c|}{ F-ratio } \\
\hline Regression & 430.136 & 8 & 56.267 & \multicolumn{2}{|c|}{$73.351 * *$} \\
\hline Residual & 257.624 & 391 & 0.915 & \multicolumn{2}{|c|}{-} \\
\hline \multicolumn{6}{|l|}{$* *$ Significant at 0.01 level } \\
\hline \multicolumn{6}{|c|}{ Test for Existence of Correlation Amongst the Error Terms } \\
\hline \multicolumn{6}{|c|}{$\begin{array}{l}\text { Durbin-Watson D Statistic }=2.487 * * * ; \text { First Order Autocorrelation }=0.196 * * * \text { Not significant at } 0.05 \text { level, where the null hypothesis (Ho) } \\
\text { involved was "there is no correlation amongst the residual (error) terms in the regression model". The null hypothesis was not rejected. Thus, } \\
\text { absence of correlation and error terms cancelling each other is proved }\end{array}$} \\
\hline
\end{tabular}

challenges of smart cities for the modern and urban planning and design. The result of ANOVA (Regression Analysis) test indicates significant at 0.01 level. The consequence from Table 4 shows that all eight fundamental elements together impact the Cyber security and Forensic Investigation influence element. So, Null Hypothesis is rejected. The t-test values of Limited of Energy Resources, Lack of IT Infrastructure, Fund Generation and Artificial Intelligence effects are significant at 0.01 level. The results from Table 4 related to t-test indicate the impacts of six strategies together on future challenges of smart cities for the modern and urban planning and design in Saudi Arabia. So, Null Hypothesis is rejected.

\section{CONCLUSION}

The development of smart city is the innovative footstep to ensure the overall facilities for the citizens. The modern IT infrastructure and management approaches in smart cities ensure the best quality of balancing life with ease of doing business, quality of education, research and development, there will be a limited period of time to survive with those resources. The production of renewable resources is the revolutionary initiatives to overcome future challenges.

\section{LIMITATIONS}

This research study recognizes and reveals to address the probable limitations that can open up the new window for further research activities. First, the stakeholders from diverse background and responses can various from one person to another. Second, the demographic factors vary the responses from one person to another. For the reason that, some various such as age of people or time of life, and economic conditions impact the respondents in various directions towards future challenges and effective strategies for defeating those questions and challenges. Finally, the present literature and respective research articles contains incomplete ideas and descriptions regarding the future challenges and effective strategies for overcoming those challenges. 


\section{FUTURE RESEARCH}

The research study identified the gap between the outcomes of present available literatures and actual requirements in the corporate world, society regarding the future challenges and effective strategies for overcoming those challenges. The outcomes of the research study are the inspiration and gives directions for future research investigations. The innovative and realistic strategies can overcome the future challenges for smart cities in Saudi Arabia [21] [34]. Once the initiative takes place, the relevant research study will encourage on identifying drawbacks and suggesting time to time to overcome all those drawbacks.

\section{ACKNOWLEDGEMENT}

I would like to express my special thanks of gratitude to my team works who supported me from Taibah University and King Abdulaziz City for Science and as well as our principal the IT department from Madinah Municipality who gave me the golden opportunity to do this wonderful project on the topic Cyber Security, Forensics And Its Impact On Future Challenges In Saudi Arabia Smart Cities, Case Study On The Modern, Urban Planning And Design, which also helped me in doing a lot of Research and i came to know about so many new things I am really thankful to them. Secondly i would also like to thank my parents, small family and friends who helped me a lot in finalizing this project within the limited time frame.

\section{REFERENCES}

1. Antar A. and Faez Saad Al-Shihri. (2015). "Rapid Urbanization and Sustainability in Saudi Arabia: The Case of Dammam Metropolitan Area", Journal of Sustainable Development, 8(9), pp 52-65. https://doi.org/10.5539/jsd.v8n9p52

2. [2] Adel S. Elmaghraby and Michael M. Losavio. (2014). "Cyber security challenges in Smart Cities: Safety, security and privacy", Journal of Advanced Research, 5(4), pp 491-497.

3. [3] Ashwan, M. (1990). "The population growth of Riyadh city in Saudi Arabia", PhD Thesis, UK: University of Durham, pp. 123-125.

4. [4] Assead, S. (2007). "The rise of consumerism in Saudi Arabian society", International Journal of Commerce and Management, 17(2), pp. 73-104. https://doi.org/10.1108/10569210710774767

5. [5] Atash, F. (1993). "Fragmentation of the urban fabric: the experience of Middle Eastern and North African Cities", The International J. of Urban policy and planning, 10 (4), pp. 313-325.

6. [6] Balchin, P. and Stewart, J. (2001). "Social housing in Latin America: Opportunities for affordability in a region of housing need", Journal of Housing and the Built Environment, 16(1), pp.333-341.

7. [7] Ben-Israel, A. (2008). "Renaming space and reshaping identities: The case of the Bedouin town of Hura in Israel”, Scholarly Journals, 8(2), pp. 65-92.

8. [8] Benton-Short, L. Price, M. Friedman, S. (2005). "Globalization from Below: The Ranking of Global
Immigrant Cities", International Journal of Urban and Regional Research, 29 (4), pp. 945-959.

https://doi.org/10.1111/j.1468-2427.2005.00630.x

9. [9] Chamratrithirong, A. (2007). "Research on Internal Migration in Thailand: The State of Knowledge", Journal of Population and Social Studies, 16(1), pp. 1-20.

10. [10] Cohen, B. (2004). "Urban Growth in Developing Countries: A Review of Current Trends and a Caution Regarding Existing Forecasts", Review of World Development, 32(1), pp. 23-51.

11. [11] Egset, W. (2000). "Poverty in the Middle East and North Africa: A survey of data and recent trends", Ministry for Foreign Affairs, Stockholm, pp. 235-239.

12. [12] El Araby, M. (2002). "Urban growth and environmental degradation: The case of Cairo, Egypt. Cities, 19(6), pp. 389-400.

13. [13] Elliot, S. R. (2005). "Sustainability: An Economic Perspective, Resources Conservations and Recycling”, J. of Economics", 44(1), pp. 263-277 https://doi.org/10.1016/j.resconrec.2005.01.004

14. [14] Flanagan, R. J. and Ulman, L. (1974). "Worker discontent and workplace behavior", J. of Industrial Relations, 13(2), pp. 101-123.

15. [15] Foxman, N. (1994). "Succeeding in outsourcing is the cultivate the outsourcing relationship", J. of Information systems management, 11(1), pp. 77- 80.

16. [16] Graham, S. (2004). "Postmortem city, Towards an urban geopolitics", The International J. of Urban policy and planning, 8(2), pp. 165-196.

17. [17] Graham, S. (2006). "Cities and the War on terror", International Journal of Urban and Regional Research, 30(2), pp.255-276.

18. [18] Henerson, V. (2002). "Urbanization in Developing Countries", The World Bank Research Observer, 17(1), pp. 89-112.

19. [19] Harter, James K.; Schmidt. (2002). "Business unit level relationship between employee satisfaction, employee engagement, and business outcomes: A meta-analysis", Journal of Applied Psychology, 87(2), pp. 268-279

https://doi.org/10.1037/0021-9010.87.2.268

20. [20] Hart S. L., M. B. Milstein. (2003). "Creating Sustainable Value", Academy of Management Executive, 17(2), pp. 56-67

21. [21] Juliana, P. (1999). "Vertical integration and long-term contracts related to coal-buring electric generating plants", J. of Law Economics and Organization, 1 (1), pp. 33-80.

22. [22] Kahn, William A. (1990). "Psychological Conditions of Personal Engagement and Disengagement at Work", Academy of Management Journal, 33 (4); pp. 692-702.

23. [23] Kee-hung and Ramus. (2015). "Empirical study on Information Technology and Environmental Concern", J. of California Management Review, 52(3), pp 16-26.

24. [24] Klein, B., and Alchian, A. (1978). "Vertical integration, appropriable rents, and the competitive contracting process", J. of Law and Economics, 21 (2), pp. 297-326. 
25. [25] Liesbet van Zoonen. (2016). "Privacy concerns in smart cities", Government Information Quarterly, 33(3), pp. 472-480.

https://doi.org/10.1016/j.giq.2016.06.004

26. [26] Mahua B., Suplab K. Podder, and Debabrata Samanta. (2019). "Factors that influence Sustainable Education with respect to Innovation and Statistical Science", International Journal of Recent Technology and Engineering (IJRTE), 7(5S2), pp. 234-238.

27. [27] Maroš Lacinák and Jozef Ristvej. (2017). "Smart city, Safety and Security", J. of Procedia Engineering, 12(2), pp. 192-196.

28. [28] McKay, Avery, Morris. (2008). "Mean racial and ethnic differences in sales performance: The moderating role of diversity climate", Personnel Psychology, 61(2), pp 349-374.

29. [29] Michael, C. and Spector, P. (1982). "Causes of employee turnover: a test of the Mobely, Griffeth, Hand and Meglino model", J. of Applied Psychology, 67 (1), pp. 53-59.

30. [30] Milgrom, P. and Roberts, J. (1995). "Complementarities, strategy, structure, and organizational change in manufacturing", J. of Accounting and Economics, 19(3), pp. 179-208.

31. [31] Podder S.K., Samanta D., Gurunath R. (2020). "Impact of Business Analytics for Smart Education System and Management Functions", In: Sharma H., Govindan K., Poonia R., Kumar S., El-Medany W. (eds) Advances in Computing and Intelligent Systems. Algorithms for Intelligent Systems. Springer, Singapore, pp 479-488

32. [32] Shuckand, W. (2011). "Effectiveness of implementation of Innovation Technology in Youth Education", Journal of Academic Research and Development, 3(4), pp 111-118

33. [33] Tadelis, S. (2002). "Complexity, flexibility and the make-or-buy decision", J. of Management Studies, 92 (2), pp. 433-437.

34. [34] Zoogah, D. (2011). "The dynamics of Green Management behaviors: A Cognitive Social Information Processing Approach", German Journal of Personnel Issues, 25(1), pp 117-139. https://doi.org/10.1177/239700221102500204 